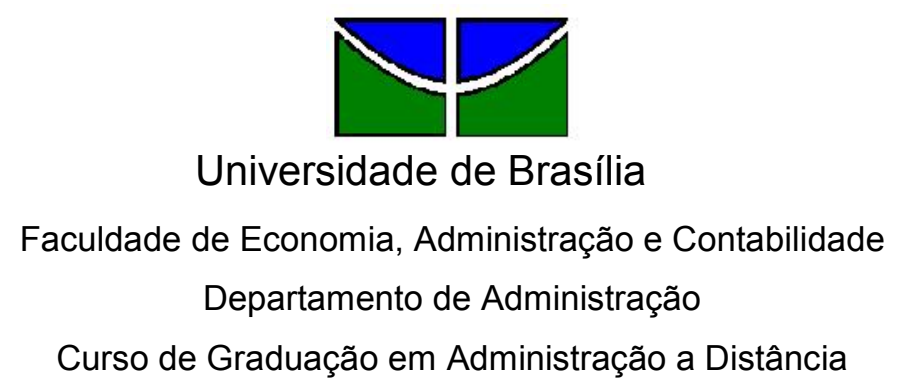

SILVIA LETICE RODRIGUES OLIVEIRA

\title{
INSERÇÃO DE PESSOAS COM DEFICIÊNCIA AUDITIVA NO MERCADO DE TRABALHO: CAPACITAÇÃO E TREINAMENTO
}

Brasília - DF 


\section{SILVIA LETICE RODRIGUES OLIVEIRA}

\section{INSERÇÃO DE PESSOAS COM DEFICIÊNCIA AUDITIVA NO MERCADO DE TRABALHO: CAPACITAÇÃO E \\ TREINAMENTO}

Monografia apresentada a Universidade de Brasília (UnB) como requisito parcial para obtenção do grau de Bacharel em Administração.

Professor Orientador: Mestre Antonio Isidro da Silva Filho

Tutor Orientador: Especialista Maira Pinto Cauchioli Rodrigues

$$
\begin{gathered}
\text { Brasília - DF } \\
2010
\end{gathered}
$$


Oliveira, Silvia Letice Rodrigues.

Inserção de Pessoas com Deficiência Auditiva no Mercado de Trabalho: Capacitação e Treinamento / Silvia Letice Rodrigues Oliveira. - Brasília, 2010.

$55 \mathrm{f}$. : il.

Monografia (bacharelado) - Universidade de Brasília, Departamento de Administração - EaD, 2010

Orientador: Professor Mestre. Antonio Isidro da Silva Filho, Departamento de Administração.

1. Inserção da Pessoa com Deficiência. 2. Educação e Treinamento. 3. Mercado de Trabalho. 4. Gestão de Pessoas I. Título. 


\section{SILVIA LETICE RODRIGUES OLIVEIRA}

\section{INSERÇÃO DE PESSOAS COM DEFICIÊNCIA AUDITIVA NO MERCADO DE TRABALHO: CAPACITAÇÃO E TREINAMENTO}

A Comissão Examinadora, abaixo identificada, aprova o Trabalho de Conclusão do Curso de Administração da Universidade de Brasília do (a) aluno (a)

\section{Silvia Letice Rodrigues Oliveira}

Mestre Antonio Isidro da Silva Filho
Professor Orientador

Especialista Maira Pinto Cauchioli Rodrigues Tutor Orientador

Késia Rozzett Oliveira

Professor-Examinador

Brasília, 4 de dezembro de 2010 
Aos surdos, que lutam constantemente por respeito e para serem incluídos no mercado de trabalho. Que tenham persistência nesse desafio e que valorizem as suas habilidades. 


\section{AGRADECIMENTOS}

Agradeço a Deus, o Autor da Vida;

Aos meus pais, pelo amor, cuidado, carinho e dedicação;

Ao Athos pelo carinho, ajuda e compreensão;

Às pessoas do meu convívio, família, amigos pelo constante apoio e incentivo;

À minha orientadora Maira Pinto Cauchioli Rodrigues, pela atenção e paciência;

À minha prima Verônica, amiga de todas as horas, sempre presente durante esses anos de curso;

Aos meus colegas da turma $\mathrm{J} 1$;

Ao corpo docente da UnB e aos tutores pela oportunidade de aprofundamento dos conhecimentos;

Aos participantes da pesquisa, pela disposição em ajudar. 
"Não é a surdez que define o destino das pessoas, mas o olhar da sociedade sobre a surdez".

Vygotsky 


\section{RESUMO}

O trabalho pode ser considerado um mecanismo de inserção social. Para as pessoas com deficiência auditiva, a inserção no mercado de trabalho não é fácil. As exigências são muitas, principalmente na área educacional, e ainda existem muitas falhas e omissões na educação e no treinamento de surdos. Diante das dificuldades encontradas para a inclusão de pessoas com surdez, este estudo visa descrever um programa de inserção de pessoas com deficiência auditiva no mercado de trabalho, caracterizar as percepções dos atores envolvidos no projeto sobre as competências existentes e necessárias para o desenvolvimento das atividades profissionais propostas. Como instrumentos de pesquisa foram utilizados roteiros de entrevistas estruturadas, observação do local de trabalho e documentos. Os dados foram tratados utilizando a técnica de análise de conteúdo. Os resultados obtidos foram satisfatórios, revelando a importância do treinamento e da qualificação profissional para que haja uma inclusão efetiva, resgatando o direito de cidadania e a valorização da diversidade humana.

Palavras-chave: Surdez. Mercado de trabalho. Educação e Treinamento. 


\section{LISTA DE QUADROS}

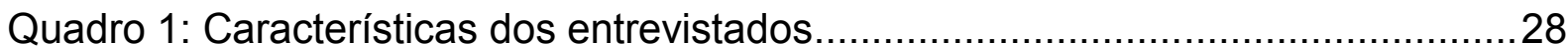

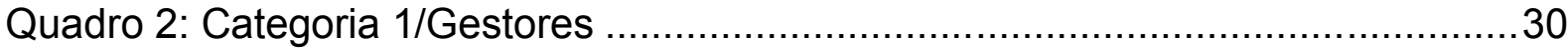

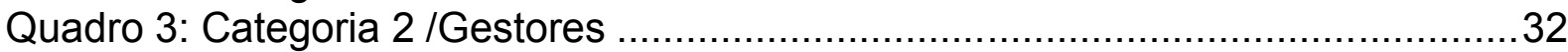

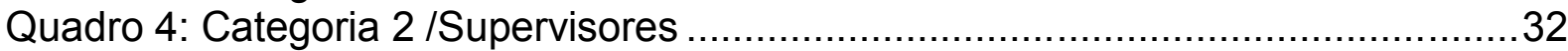

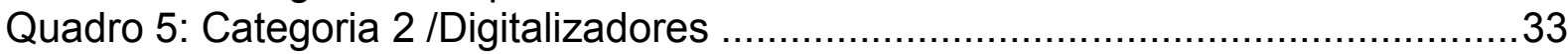

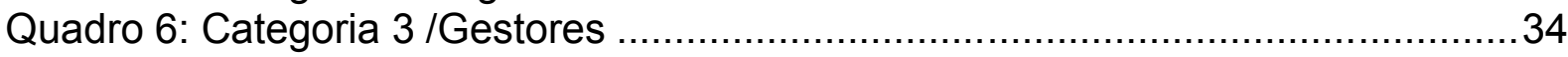

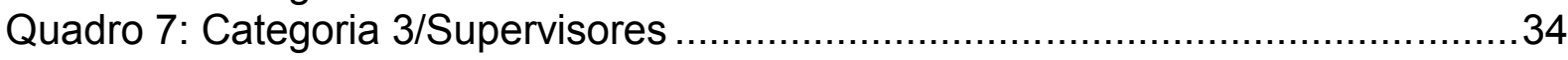

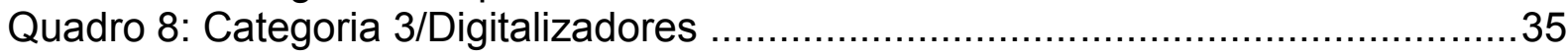

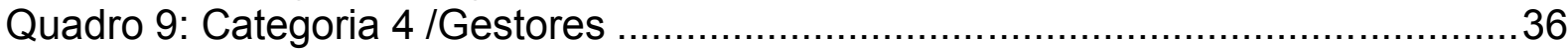

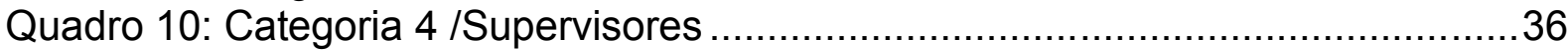

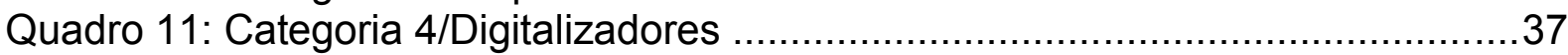

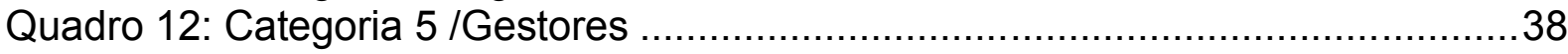

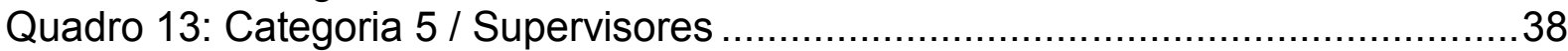

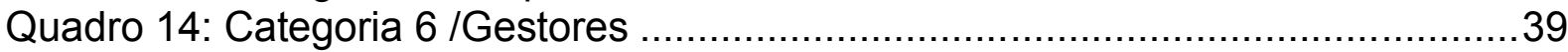

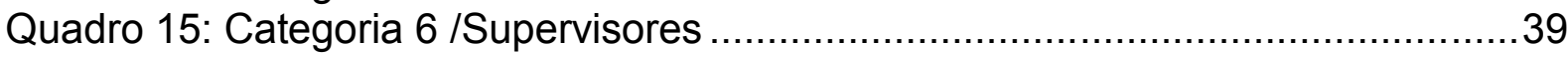




\section{LISTA DE ABREVIATURAS E SIGLAS}

APADA - Associação dos Pais e Amigos dos Deficientes Auditivos

APAE - Associação de Pais e Amigos dos Excepcionais

CETEFE- Centro de Treinamento em Educação Física Especial

FENEIS - Federação Nacional de Educação e Integração dos Surdos

IBGE - Instituto Brasileiro de Geografia e Estatística

INES - Instituto Nacional de Educação de Surdos

INSM - Instituto Nacional de Surdos-Mudos

LIBRAS - Língua Brasileira de Sinais

STJ - Superior Tribunal de Justiça 


\section{SUMÁRIO}

1 INTRODUÇÃO

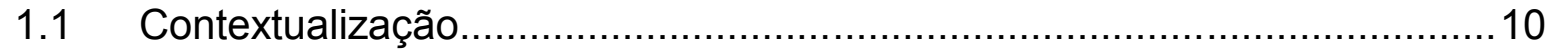

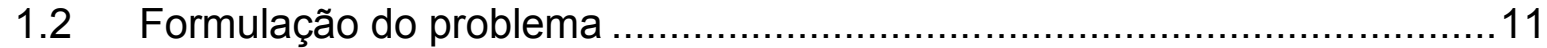

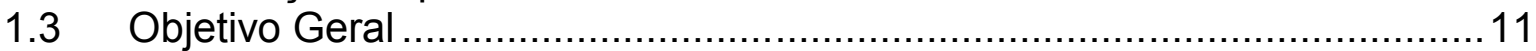

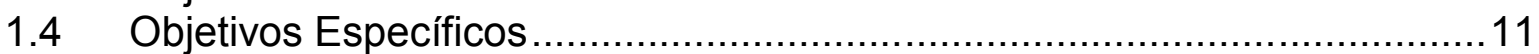

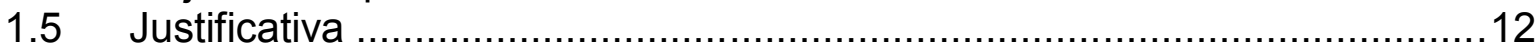

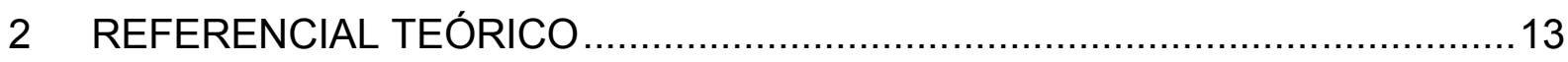

2.1 Surdez e deficiência auditiva: conceitos e principais abordagens .............13

2.2 Breve histórico da educação de surdos no Brasil ....................................14

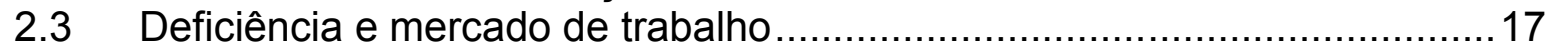

2.4 Deficiente auditivo e mercado de trabalho ...........................................21

2.5 Educação, treinamento e qualificação de surdos para o trabalho................22

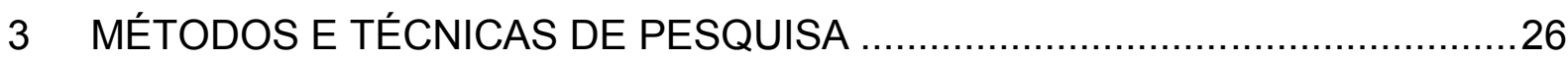

3.1 Tipo e Descrição Geral da Pesquisa ....................................................26

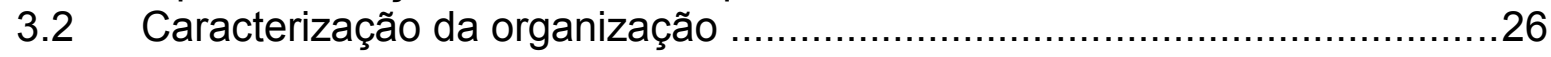

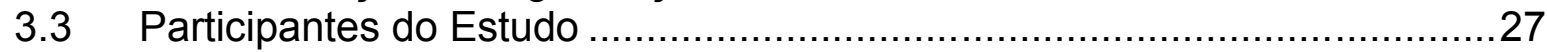

3.4 Caracterização dos instrumentos de pesquisa .....................................28

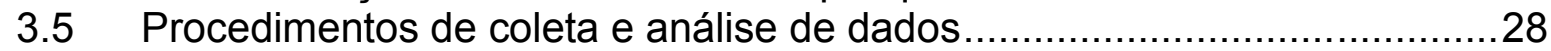

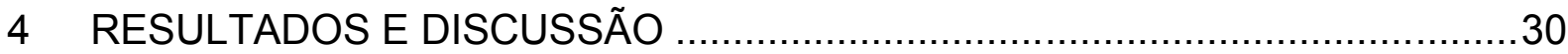

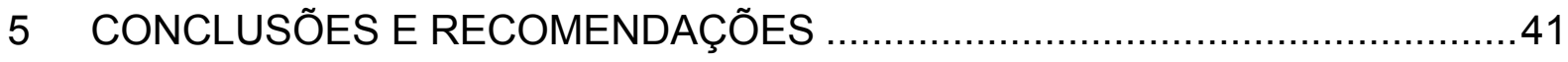

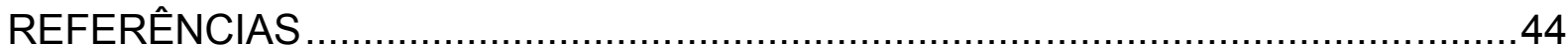

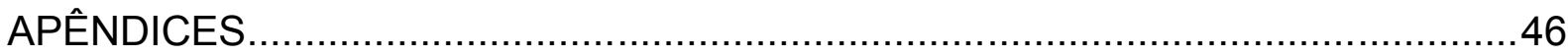

Apêndice A - Roteiro de Entrevista 1 ........................................................47

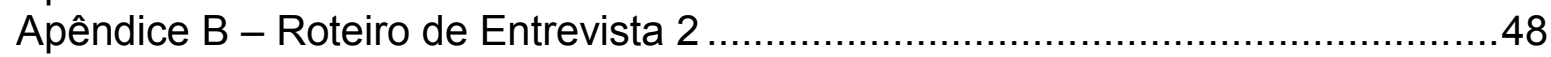

Apêndice C - Roteiro de Entrevista 3 ........................................................

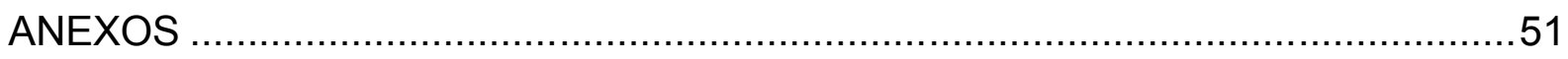

Anexo A - Carta para a Organização ……..................................................52

Anexo B - Apresentação da pesquisa: orientações gerais para os entrevistados.53 Anexo C - Fluxograma do Processo de Educação Profissional e Colocação no Trabalho 


\section{INTRODUÇÃO}

A Convenção de Guatemala no seu artigo $1^{\circ}$ define deficiência como uma restrição física, mental ou sensorial, de natureza permanente ou transitória, que limita a capacidade de exercer uma ou mais atividades essenciais da vida diária, causada ou agravada pelo ambiente econômico e social. Pode ser exemplificada a deficiência física, mental, auditiva, visual.

A definição de deficiência auditiva sempre foi muito discutida. Alguns tentam diferenciar surdez de deficiência auditiva. Para Moores (2001), uma pessoa é considerada surda quando a audição está prejudicada a ponto de impedir a compreensão da fala através do ouvido apenas, com ou sem o uso de aparelho auditivo. Já uma pessoa deficiente auditiva é aquela cuja audição esteja prejudicada a ponto de dificultar, mas não impedir a compreensão da fala através do ouvido apenas, com ou sem o uso de aparelho auditivo.

Segundo Skliar (1999), e também por alguns estudos das comunidades surdas, a surdez pode ser pensada em termos de minoria lingüística, em que a língua utilizada não é a Língua Portuguesa e sim a Língua Brasileira de Sinais (LIBRAS). Por fazer parte então de uma "minoria linguística" o surdo acaba se apresentando em desvantagem em relação às outras pessoas, nas mais diversas esferas do cotidiano.

No mercado de trabalho não é diferente. As exigências para que uma pessoa ingresse no mercado de trabalho são muitas, principalmente na área educacional.

\subsection{Contextualização}

Existem lacunas na educação e no treinamento de surdos para o mercado de trabalho. Observa-se que a maioria participa de atividades de menor complexidade, sendo que, como o cognitivo na maioria das vezes é preservado, poderiam exercer também atividades mais complexas.

Fala-se em igualdade de direitos, acessibilidade, mas até que ponto isso vem acontecendo? Sendo assim, é relevante pesquisar esse tema, relacionando como é 
a preparação dessas pessoas para o mercado de trabalho e as necessidades de aprimoramento/aperfeiçoamento que elas encontram após iniciarem suas atividades profissionais, já que vivem em um mundo em que a maioria das pessoas é ouvinte.

\subsection{Formulação do problema}

Apresenta-se o seguinte problema de pesquisa:

Qual a percepção dos atores envolvidos no processo de inserção do surdo/deficiente auditivo no mercado de trabalho sobre as competências existentes e as necessárias para o seu aperfeiçoamento/aprimoramento?

\subsection{Objetivo Geral}

Caracterizar a percepção dos atores envolvidos no processo de inserção do surdo/deficiente auditivo no mercado de trabalho sobre as competências existentes e as necessárias para o seu aperfeiçoamento/aprimoramento profissional.

\subsection{Objetivos Específicos}

- Descrever um programa de inserção de pessoas com deficiência auditiva no mercado de trabalho;

- Identificar quais são as competências e saberes existentes e necessários para o desempenho das atividades profissionais propostas.

- Caracterizar as percepções dos atores envolvidos com esse programa sobre as competências existentes e as necessárias para o desempenho das atividades profissionais propostas. 


\subsection{Justificativa}

O trabalho pode ser considerado um mecanismo de inserção social. Além de ser uma fonte necessária para o sustento e sobrevivência, é também um meio de realização pessoal.

A integração da pessoa com deficiência ao mercado de trabalho é prevista por lei. Existe a reserva de vagas, mas é importante saber se esses trabalhadores estão preparados para ingressarem e realizarem o trabalho com excelência.

Para as pessoas com deficiência auditiva, a inserção no mercado de trabalho não é fácil. As exigências são muitas, principalmente na área educacional, e ainda existem muitas falhas e omissões na educação e no treinamento de surdos. Observa-se que a maioria participa de atividades de menor complexidade, sendo que, como o cognitivo na maioria das vezes é preservado, poderiam exercer também atividades mais complexas.

Considerando o que foi relatado, observa-se a relevância de se pesquisar as ações que estão sendo realizadas para integrar o surdo ao mercado de trabalho. É uma oportunidade de se conhecer a realidade da pessoa com deficiência, verificar se a lei está sendo cumprida e ainda de reflexão sobre a área de treinamento e qualificação de profissionais com deficiência. É também uma oportunidade de constatar a visão que os empregadores têm sobre a pessoa com deficiência auditiva e mostrar a importância de uma inclusão efetiva, humanizando os postos de trabalho e resgatando o direito de cidadania e a valorização da diversidade humana nesses ambientes.

Escolheu-se um ambiente organizacional, o STJ (Superior Tribunal de Justiça), pois está sendo realizado, nesse órgão, um trabalho com várias pessoas com deficiência auditiva na área de digitalização de processos. Sendo assim, considera-se viável a pesquisa proposta. 


\section{REFERENCIAL TEÓRICO}

\subsection{Surdez e deficiência auditiva: conceitos e principais abordagens}

Durante algum tempo, pessoas que apresentavam surdez eram chamadas de surdos-mudos. "Quando se refere ao surdo, a palavra mudo não corresponde à realidade dessa pessoa. O diminutivo mudinho denota que o surdo não é tido como uma pessoa completa" (SASSAKI, 2003, p.3).

Para alguns autores existe diferença entre surdez e deficiência auditiva. Moores (2001) afirma que uma pessoa é considerada surda quando a audição está prejudicada a ponto de impedir a compreensão da fala através do ouvido apenas, com ou sem o uso de aparelho auditivo. Já uma pessoa deficiente auditiva é aquela cuja audição esteja prejudicada a ponto de dificultar, mas não impedir a compreensão da fala através do ouvido apenas, com ou sem o uso de aparelho auditivo.

O Decreto $n^{\circ} 3.298$, de 20 de dezembro de 1999 define deficiência auditiva e apresenta a classificação em graus:

Deficiência auditiva - perda parcial ou total das possibilidades auditivas sonoras, variando de graus e níveis na forma seguinte:

a) de 25 a 40 decibéis ( $\mathrm{dB})$ - surdez leve;

b) de 41 a $55 \mathrm{~dB}$ - surdez moderada;

c) de 56 a $70 \mathrm{~dB}$ - surdez acentuada;

d) de 71 a $90 \mathrm{~dB}$ - surdez severa;

e) acima de $91 \mathrm{~dB}$ - surdez profunda; e

f) anacusia;

O Decreto $N^{\circ} 5.626$, de 22 de dezembro de 2005 traz a seguinte definição:

Art. 2o Para os fins deste Decreto, considera-se pessoa surda aquela que, por ter perda auditiva, compreende e interage com o mundo por meio de experiências visuais, manifestando sua cultura principalmente pelo uso da Língua Brasileira de Sinais - Libras. 
Para Skliar (1999) o uso do termo surdo ou deficiente auditivo aponta para uma diferença de concepção da surdez. Destacam-se aqui duas concepções: a concepção clínico-patológica e a concepção sócio-antropológica.

A concepção clínico-patológica considera a surdez como uma deficiência a ser curada através de recursos como treinamento de fala e audição, uso precoce de aparelhos de amplificação do som, intervenções cirúrgicas como o implante coclear, etc.

A concepção sócio-antropológica, por outro lado, concebe a surdez como uma diferença a ser respeitada e não uma deficiência a ser eliminada. Deve-se considerar a pessoa surda como pertencente a uma minoria com direito à língua e cultura próprias (SKLIAR,1999).

Ainda segundo Skliar (1999), e também por alguns estudos das comunidades surdas, a surdez pode ser pensada em termos de minoria lingüística, em que a língua utilizada não é a Língua Portuguesa e sim a Língua Brasileira de Sinais (LIBRAS). Por fazer parte então de uma "minoria linguística" o surdo acaba se apresentando em desvantagem em relação às outras pessoas, nas mais diversas esferas do cotidiano.

Neste trabalho são utilizados os termos deficiência auditiva e surdez com o mesmo sentido, privilegiando a concepção sócio-antropológica. A seção a seguir relata de forma sucinta as ações de educação do surdo no Brasil num período recente da história.

\subsection{Breve histórico da educação de surdos no Brasil}

Os surdos há algum tempo eram considerados débeis, deficientes mentais, impossibilitados de aprender. Goldfeld (1993) faz um breve relato da história da educação dos surdos no Brasil, de meados do século XIX até os dias mais atuais.

A autora informa que em 1855 chegou ao Brasil um professor surdo, Hernest Huet, trazido da França por D. Pedro II. Dois anos depois, em 1857, foi criado o Instituto Nacional de Educação de Surdos-Mudos (INSM), hoje Instituto Nacional de Educação de Surdos (INES). Em 1911 a filosofia adotada para a educação de surdos foi o oralismo. Segundo a filosofia do oralismo, a pessoa com surdez deve 
ser integrada à comunidade de ouvintes e ter então a condição de desenvolver a língua oral (GOLDFELD, 1993. p.33).

Mesmo com a filosofia do oralismo sendo predominante nessa época, a Língua de Sinais sobreviveu até 1957, pois mesmo proibida, os alunos a usavam nos corredores e pátios da escola (GOLDFELD, 1993, p. 32). A língua de sinais pode ser considerada como a língua própria da comunidade surda, em que são utilizados gestos, movimento das mãos, expressões faciais e corporais. É uma modalidade de língua vísuo-espacial (SALLES, et. al., 2004, p.17).

No final da década de 70 chegou então ao Brasil a filosofia da Comunicação Total. Segundo essa abordagem, existe a preocupação da comunicação entre surdos e surdos e entre surdos e ouvintes. Essa filosofia se preocupa com o aprendizado da língua oral, mas também defende a utilização de recursos espaço-viso-manuais.

Atualmente as três abordagens convivem no Brasil, mas existe um forte movimento para o uso da LIBRAS (Língua Brasileira de Sinais) tendo sido inclusive regulamentada a chamada Lei de Libras (Lei $\mathrm{n}^{\circ} 10.436$ de 24 de abril de 2002, Decreto_nº 5.626 de 22 de dezembro de 2005).

Em relação ao ensino profissionalizante existem algumas associações que se propõem a preparar o surdo para o mercado de trabalho. Há relatos de que o ensino profissionalizante para surdos no Brasil começou por volta de 1857, de forma mais sistemática.

Madalena Klein (2006) apresenta um pouco da história da educação profissional de surdos no Brasil:

A preocupação com a capacitação para o mercado de trabalho pode ser
observada nos projetos educacionais para surdos, desde a fundação do
antigo Instituto Nacional de Surdos-Mudos (INSM), em 1857, primeira
escola de surdos no Brasil. Oficinas laborais dentro das escolas, como
também formulações mais gerais envolvendo programas governamentais,
têm, desde lá, caracterizado a diversidade de práticas voltadas à formação
profissional que se articula nos espaços surdos - as escolas de surdos e as
diferentes instâncias dos movimentos sociais organizados como
associações, clubes, ou seja, espaços nos quais foram/ são organizados
programas voltados para a formação profissional dos surdos. (KLEIN, 2006,
p.442)

$\mathrm{Na}$ atualidade, a FENEIS (Federação Nacional de Educação e Integração dos Surdos) tem apoiado os surdos, promovendo cursos de capacitação profissional em parceria com diversas empresas. A FENEIS é uma entidade filantrópica, sem fins lucrativos com finalidade sócio-cultural, assistencial e educacional que tem por 
objetivo a defesa e a luta dos direitos da Comunidade Surda Brasileira. É filiada a Federação Mundial dos Surdos e suas atividades foram reconhecidas como de Utilidade Pública Federal, Estadual e Municipal. Segundo a FENEIS, a contratação do surdo é um investimento para a empresa, pois há um aumento da atenção concentrada no ambiente de trabalho, valorização do emprego pelo surdo devido à dificuldade de inserção no mercado de trabalho, descoberta de talentos desconhecidos e potenciais e enriquecimento do grupo funcional. (FENEIS, 2010)

Outra associação importante é a APADA (Associação dos Pais e Amigos dos Deficientes da Audição), tendo representação em vários estados brasileiros. A APADA/DF tem por finalidades: promover a assistência social, a cultura, prestação de serviços educacionais e a saúde; promover o voluntariado, a ética, a paz, a cidadania, os direitos humanos, a democracia e outros valores universais; promover estudos e pesquisas, produção e divulgação de informações, conhecimentos técnicos e científicos; promover cursos, palestras e outros eventos, nacionais e internacionais; promover auxílio, orientação, atendimento médico e psicológico aos deficientes auditivos carentes e a seus familiares, bem como promover a integração família, escola-comunidade; promover a integração no mercado de trabalho; celebrar convênios e parcerias com órgãos e entidades públicas ou instituições congêneres e com a iniciativa privada, visando à consecução de seus objetivos (APADA, 2010).

Destaca-se também o Centro de Treinamento de Educação Física Especial (CETEFE). Para promover o resgate social da pessoa com deficiência, o CETEFE adotou o esporte, a capacitação profissional e a cultura como veículos transformadores. Pelo reconhecimento das ações desenvolvidas no Distrito Federal e no Brasil, o CETEFE recebeu os Títulos de Utilidade Pública e Assistência Social Federal/Distrital. Os programas são desenvolvidos em parceria com as Secretarias de Educação, Esporte, Justiça, Direitos Humanos e Cidadania do Distrito Federal; Escola Nacional de Administração Pública e Ministério do Esporte. O diferencial do CETEFE consiste em atender gratuitamente às pessoas com deficiência física, auditiva, intelectual e visual, em programas esportivos, culturais e capacitação profissional, sendo a única entidade do país com maior número de modalidades paraolímpicas, culturais e profissionais para todos os grupos de deficiência. (CETEFE, 2010) 


\subsection{Deficiência e mercado de trabalho}

Conforme Nohara et. al. (2009), o trabalho confere sentido à vida, sendo símbolo de atualização e de realização ao proporcionar condições para a vinculação de um indivíduo a um grupo. Proporciona condições para aprendizagem e desenvolvimento de competências, garante segurança, independência financeira e contribui para a autonomia do indivíduo.

O trabalho contribui para a confiança e auto-estima e tem papel fundamental, pois proporciona aprendizagem, crescimento, transformação de conceitos e atitudes e remuneração (BATISTA, et al., 1998).

Ingressar no mercado de trabalho tem sido um desafio para muitas pessoas com deficiência. Todo o histórico de preconceito e discriminação já foi relatado em diversos artigos sobre o tema.

A gestão da diversidade e a inclusão de pessoas com deficiência no trabalho vêm se caracterizando como um tema relevante na área dos estudos organizacionais. Carvalho-Freitas et.al. (2009) mostra uma análise da produção acadêmica nacional dos últimos 20 anos sobre o tema e conclui que, mesmo sendo importantes, estudos na área de gestão da diversidade são ainda muito recentes e as pesquisas nessa área tem foco principal em educação especial.

Estudos e pesquisas na área de inserção de pessoas com deficiência no mercado de trabalho apontam como principais entraves: falta de qualificação profissional; descrédito dos gestores sobre as reais qualificações do candidato; presença de barreiras físicas e atitudinais; preconceitos; ausência de ações de sensibilização do cliente externo; assédio moral; inexistência de critérios para recrutamento, seleção e desenvolvimento dessas pessoas. (NUNES SOBRINHO, 2008, p.13)

Estudos de Tanaka e Manzini (2005) mostraram que os cargos ocupados por funcionários com deficiência exigem pouca qualificação e o seu treinamento é geralmente realizado no próprio local de trabalho.

"A dificuldade para se relacionar com uma pessoa que possui deficiência, até por não saber como lhe dirigir, muitas vezes acabaria tornando um obstáculo para as empresas quando estas necessitassem contratar um funcionário com essa condição (...). A falta de conhecimento do potencial das pessoas com deficiência, entre outras variáveis, consistia num dos 
grandes motivos que impediam ou dificultavam a contratação dessa população pelas empresas." (TANAKA; MANZINI; 2005, p.287).

Mas essa situação está mudando aos poucos. Segundo Carvalho (2009), conseguir um lugar no mundo do trabalho competitivo facilita a aceitação social da pessoa com deficiência.

Conforme Carvalho-Freitas (2009), à medida que a dignidade do homem, seu direito à igualdade de oportunidades e participação na sociedade passaram a preocupar inúmeros pensadores, a história começou a mudar.

No Brasil isso pode ser percebido pelas diversas leis que garantem direitos às pessoas com deficiência, entre eles o ingresso no mercado de trabalho. Destacamse aqui algumas delas.

A Constituição Federal de 1998 informa, no seu artigo $5^{\circ}$, que todos são iguais perante a lei, sendo garantido o direito à vida, à liberdade, à igualdade, à segurança e à propriedade. Além disso, garante que a lei reservará percentual de cargos e empregos públicos para pessoas portadoras de deficiência. Trata ainda de treinamentos para pessoas com deficiência.

Art. 227. É dever da família, da sociedade e do Estado assegurar à criança e ao adolescente, com absoluta prioridade, o direito à vida, à saúde, à alimentação, à educação, ao lazer, à profissionalização, à cultura, à dignidade, ao respeito, à liberdade e à convivência familiar e comunitária, além de colocá-los a salvo de toda forma de negligência, discriminação, exploração, violência, crueldade e opressão.

$\S 1^{\circ}$ - O Estado promoverá programas de assistência integral à saúde da criança e do adolescente, admitida a participação de entidades não governamentais e obedecendo aos seguintes preceitos:

(...)

II - criação de programas de prevenção e atendimento especializado para os portadores de deficiência física, sensorial ou mental, bem como de integração social do adolescente portador de deficiência, mediante o treinamento para o trabalho e a convivência, e a facilitação do acesso aos bens e serviços coletivos, com a eliminação de preconceitos e obstáculos arquitetônicos. (BRASIL, 1988)

A lei que reserva o percentual de cargos e empregos públicos para pessoas com deficiência é a lei 8112 de 1990, conhecida como Regime Jurídico dos Servidores da União:

Art. $5^{\circ}$ São requisitos básicos para investidura em cargo público:

I - a nacionalidade brasileira;

II - o gozo dos direitos políticos;

III - a quitação com as obrigações militares e eleitorais;

IV - o nível de escolaridade exigido para o exercício do cargo;

$V$ - a idade mínima de dezoito anos;

VI - aptidão física e mental. 
$\S 1^{\circ}$ As atribuições do cargo podem justificar a exigência de outros requisitos estabelecidos em lei.

$\S 2^{\circ}$ Às pessoas portadoras de deficiência é assegurado o direito de se inscrever em concurso público para provimento de cargo cujas atribuições sejam compatíveis com a deficiência de que são portadoras; para tais pessoas serão reservadas até $20 \%$ (vinte por cento) das vagas oferecidas no concurso. (BRASIL, 1990)

Outro importante instituto legal é o Decreto 3298, de 20 de dezembro de 1999, conhecido como Lei de Cotas, que dispõe sobre a Política Nacional para a Integração da Pessoa Portadora de Deficiência, consolida as normas de proteção, e dá outras providências. Esta lei trata da equiparação de oportunidades que os órgãos da administração pública devem prestar à pessoa com deficiência; Serviços como reabilitação integral, formação profissional e qualificação para o trabalho, escolarização, orientação e promoção individual, familiar e social. Trata ainda das modalidades de inserção laboral da pessoa com deficiência.

\footnotetext{
Seção IV

Do Acesso ao Trabalho

Art. 34. É finalidade primordial da política de emprego a inserção da pessoa portadora de deficiência no mercado de trabalho ou sua incorporação ao sistema produtivo mediante regime especial de trabalho protegido.

Parágrafo único. Nos casos de deficiência grave ou severa, o cumprimento do disposto no caput deste artigo poderá ser efetivado mediante a contratação das cooperativas sociais de que trata a Lei $n^{\circ} 9.867$, de 10 de novembro de 1999.

Art. 35. São modalidades de inserção laboral da pessoa portadora de deficiência:

I - colocação competitiva: processo de contratação regular, nos termos da legislação trabalhista e previdenciária, que independe da adoção de procedimentos especiais para sua concretização, não sendo excluída a possibilidade de utilização de apoios especiais;

II - colocação seletiva: processo de contratação regular, nos termos da legislação trabalhista e previdenciária, que depende da adoção de procedimentos e apoios especiais para sua concretização; e

III - promoção do trabalho por conta própria: processo de fomento da ação de uma ou mais pessoas, mediante trabalho autônomo, cooperativado ou em regime de economia familiar, com vista à emancipação econômica e pessoal. (BRASIL, 1999)
}

Outro artigo de extrema importância é o que trata efetivamente das cotas para empresas:

Art. 36. A empresa com cem ou mais empregados está obrigada a preencher de dois a cinco por cento de seus cargos com beneficiários da Previdência Social reabilitados ou com pessoa portadora de deficiência habilitada, na seguinte proporção:

I - até duzentos empregados, dois por cento;

II - de duzentos e um a quinhentos empregados, três por cento;

III - de quinhentos e um a mil empregados, quatro por cento; ou

IV - mais de mil empregados, cinco por cento. (BRASIL, 1999) 
Além dessas leis, existem alguns acordos e documentos internacionais que tratam do tema:

- Declaração de Salamanca - Sobre Princípios, Políticas e Práticas na Área das Necessidades Educativas Especiais.

- Convenção de Guatemala - Convenção interamericana para a eliminação de todas as formas de discriminação contra as pessoas portadoras de deficiência.

- Convenção sobre os direitos das pessoas com deficiência - com o propósito de promover, proteger e assegurar o exercício pleno e eqüitativo de todos os direitos humanos e liberdades fundamentais por todas as pessoas com deficiência e promover o respeito pela sua dignidade inerente.

Desde a regulamentação da legislação aqui apresentada, as organizações têm tido então o desafio de incluir pessoas com deficiência em seus quadros de colaboradores.

Por outro lado, as organizações têm sofrido com exigências de qualidade e produtividade cada vez maiores (CARVALHO-FREITAS; MARQUES, 2009).

\begin{abstract}
Essas exigências se confrontam com o completo desconhecimento em relação às potencialidades das pessoas com deficiência e com a existência de inúmeros preconceitos entendidos com crenças generalizadas sobre características pessoais (atributos) de grupos minoritários as quais são consideradas como tipicamente negativas (CARVALHO-FREITAS; MARQUES, 2009, p. 237).
\end{abstract}

A inclusão de fato não deve ser só uma exigência da lei. Sobre esse aspecto, Ribeiro e Ribeiro (2009) destacam que a obrigatoriedade das leis se constituiu num avanço, mas, se por um lado há inclusão, por outro lado não há garantia de consciência social, nem ruptura de estereótipos e preconceitos, podendo inclusive se tornar um novo mecanismo perverso de segregação, pois garante uma oportunidade, mas não viabiliza a integração.

Diante desse quadro, ressalta-se então a importância da educação e do treinamento de pessoas com deficiência auditiva, para que ingressem eficazmente no mercado de trabalho. 


\title{
2.4 Deficiente auditivo e mercado de trabalho
}

Segundo o IBGE, Instituto Brasileiro de Geografia e Estatística, no censo 2000, 24,5 milhões de brasileiros apresentam algum tipo de deficiência, sendo $14,5 \%$ da população total. Dentre eles, 4,6 milhões possuem deficiência auditiva e 1,1 milhão são surdos, totalizando aproximadamente 5,7 milhões de pessoas. O tipo de deficiência que dificulta mais a inserção no mercado de trabalho é a deficiência mental: somente 19,3\% das pessoas que declararam apresentar deficiência mental permanente estão ocupadas. As outras incapacidades permitem uma inserção maior no mercado de trabalho: incapacidade física ou motora $(24,1 \%)$, dificuldade na audição $(34,0 \%)$ e dificuldade para enxergar $(40,8 \%)$. Para quem não apresenta nenhuma destas deficiências, a proporção de pessoas ocupadas é de $49,9 \%$.

Observa-se que a maioria das pessoas com deficiência auditiva participa de atividades de menor complexidade.

\begin{abstract}
$\mathrm{Na}$ grande maioria das vezes, não se exige que o surdo saiba ler ou escrever (empacotadores ou funcionários de limpeza), o que leva à conclusão de que eles ainda exercem atividades que requerem mais força física do que intelecto. Isso também evidencia a necessidade de melhor formação educacional para que o surdo tenha um número maior de opções de trabalho e tenha, ao menos, a chance de mostrar suas habilidades, como tem feito até agora (BORGES, et. al. 2002).
\end{abstract}

Klein (2006) descreve as características do novo perfil de trabalhador. Esse perfil exige do dispositivo de formação profissional um "novo perfil de qualificação", que procure atender às necessidades de qualidade, produtividade, competitividade e flexibilidade, consideradas " palavras-chave na economia" . "Saber fazer" não é mais suficiente para um trabalhador que almeja o sucesso. É necessário também “ conhecer e, acima de tudo, saber aprender". O "novo" trabalhador, formado pela " nova" educação profissional, deve ser preparado para a iniciativa, o imprevisto, a decisão e a responsabilidade.

Diante da demanda por profissionais mais qualificados, apresentando esse novo perfil, a necessidade de educação e treinamento torna-se então evidente. 


\subsection{Educação, treinamento e qualificação de surdos para o trabalho}

Apresentam-se aqui alguns conceitos de treinamento:

"Treinamento é o processo educacional de curto prazo e aplicado de maneira sistemática e organizada, por meio dos qual as pessoas aprendem conhecimentos, atitudes e habilidades em função de objetivos definidos." (CHIAVENATO, 2008).

"Treinamento é o conjunto de métodos usados para transmitir aos funcionários novos $e$ antigos as habilidades necessárias para 0 desempenho do trabalho." (DESSLER, 2003, p. 142).

O treinamento pode ser realizado tanto para funcionários que estejam iniciando quanto para funcionários antigos que necessitam de uma melhora no desempenho. Segundo Dessler (2003): "Treinamento, desenvolvimento ou objetivos instrucionais de modo geral são definidos como uma descrição do desempenho que os aprendizes devem ser capazes de exibir para que sejam considerados competentes."

Um bom desempenho profissional é muitas vezes atribuído a uma boa informação e a um bom treinamento.

\footnotetext{
"Análise de desempenho consiste em constatar a existência de uma deficiência significativa de desempenho e determinar se essa deficiência pode ser sanada por meio de treinamento ou outras medidas" (DESSLER, 2003, p. 142)
}

Existem diversos tipos de treinamento. Dessler (2003) elenca alguns dos principais tipos utilizados pelas empresas.

- Treinamento no trabalho: o funcionário é treinado no cargo por um trabalhador com experiência ou pelo supervisor dos treinandos.

- Treinamento por simulação: os funcionários são treinados fora do local de trabalho e aprendem no equipamento que usarão ou em similares. É utilizado quando o treinamento no trabalho é custoso ou perigoso.

- Teletreinamento: utiliza-se de técnicas de ensino a distância como videoconferências, cursos por correspondência ou aulas pela Internet. 
- Treinamento para o trabalho em equipe: esses programas têm como meta a efetividade organizacional por meio da participação dos funcionários no planejamento, na organização e no gerenciamento dos seus cargos.

- Treinamento para a diversidade: com uma força de trabalho crescentemente diversificada, mais empresas têm implementado programas de treinamento para a diversidade. Esse treinamento consiste em técnicas para melhorar a sensibilidade intercultural dos supervisores e funcionários em geral para criar relações de trabalho mais harmoniosas nas empresas.

A qualificação de surdos para o mercado de trabalho é importante para que se promova uma inclusão efetiva. Araújo (2005), em seu trabalho, destaca a importância do processo ensino-aprendizagem na qualificação de pessoas com deficiência:

\begin{abstract}
"Ocorre que, na qualificação para o mercado competitivo desse segmento de pessoas com necessidades especiais, sobretudo aquelas com comprometimento sensorial de visão e de audição, é necessário que se cuide do processo de ensino-aprendizagem no qual elas estejam implicadas a fim de desenvolver-lhes competências inerentes ao cargo que almejam. Para isso, deve ser utilizada uma mediação com recursos pedagógicos específicos, adaptações e o que se considera essencial: o conhecimento, por parte do mediador, do sujeito aprendiz e da sua deficiência, compreendendo suas singularidades. Isso contribuirá para a construção de uma aprendizagem significativa, capacitando, de fato, portadores de deficiência para assumir a posição social de trabalhadores ativos, ampliando suas perspectivas na vida." (ARAÚJO, 2005, p.2).
\end{abstract}

A própria comunidade surda tem fortalecido as suas associações com programas de qualificação e colocação no trabalho de forma bem específica. De forma geral essas associações apóiam modalidades profissionais definidas como: a do trabalho autônomo, a competitiva e a do trabalho nas oficinas protegidas ou abrigadas (ARAÚJO, 2005, p. 54).

Estudos no campo da surdez indicam que as pessoas surdas, em comparação com as ouvintes, têm uma tendência a pensar mais sobre o que está sendo percebido no momento. Seu relacionamento é mais voltado para o concreto do que para o pensamento abstrato e hipotético. (ARAÚJO, 2005).

Um trabalho realizado pela Federação Nacional das APAE's (Associação dos Pais e Amigos dos Excepcionais) propõe algumas estratégias de educação, treinamento e qualificação de pessoas com deficiência. Esse estudo é orientado aos profissionais e dirigentes. 
Nesse estudo, Batista, et. al. (1998) divide o processo de educação profissional nas seguintes etapas: etapa de preparação para o trabalho; etapa de qualificação para o trabalho; etapa de colocação no trabalho (Anexo C).

Na etapa de preparação há uma avaliação e uma pré profissionalização. A avaliação consiste de levantamento das potencialidades do portador de deficiência, especificando o grau de capacidade para a execução de uma tarefa ou desempenho de uma função ou emprego. A pré-profissonalização consiste em oferecer maior variedade de experiências de trabalho em atividades praticas, complementares e acadêmicas para que a pessoa, por meio de suas vivências, possa melhor definir seu interesse e desenvolver suas capacidades e potencialidades para o trabalho. (BATISTA, 1998, p. 21)

Na segunda etapa há o treinamento profissional que consiste em desenvolver, por meios de atividades praticas o potencial laborativo do aprendiz para executar e produzir um determinado trabalho com qualidade, quantidade e responsabilidade na função na qual ele será colocado futuramente. Já a habilitação profissional consiste em propiciar ao aprendiz, em um nível mais formal e sistematizado do que no Programa de Treinamento Profissional, a aquisição e/ou o desenvolvimento de conhecimentos e habilidades especificamente associados a uma determinada profissão ou ocupação.

A terceira etapa é a inserção da pessoa portadora de deficiência em algum tipo de atividade laborativa, competitiva e sempre condizente com o potencial, as condições físicas e as aspirações dessa pessoa e também com as disponibilidades existentes na comunidade (BATISTA, 1998, p.29)

Em relação à capacitação dos surdos para o mercado de trabalho existe ainda a particularidade da língua utilizada.

Qualquer processo que pretenda a qualificação para o trabalho incluindo pessoas surdas necessita de uma preocupação com os aspectos lingüísticos e de linguagem nessa população, a fim de que ela possa construir conceitos mais subjetivos de sua realidade laboral. Esse conceitos refletem necessidades de uma aprendizagem na ordem das competências, mais do que apenas nas habilidades para as tarefas de uma função (ARAÚJO, 2005) 
Não pode ser desconsiderado também o treinamento dos ouvintes que trabalharão diretamente com os surdos. A esse respeito, Klein (2006) descreve:

O grupo social deve encarar os obstáculos como um problema que não é solucionável apenas da parte do coletivo de surdos. Um equívoco está em que não só o surdo deve ser bilíngüe, como se ele fosse comunicar-se em LIBRAS com outros surdos e em Língua Portuguesa com ouvintes. É preciso também que haja ouvintes bilíngües; não apenas intérpretes, alguns professores e um ou outro profissional de saúde com boa vontade. Não se trata de uma questão exclusivamente "lingüística", nem de um caminho de mão única. Caso contrário, não seria um "projeto bilíngüe" e o uso da língua de sinais estaria circunscrito a poucos espaços. (KLEIN,2006) 


\section{MÉTODOS E TÉCNICAS DE PESQUISA}

\subsection{Tipo e Descrição Geral da Pesquisa}

Para alcançar o objetivo da pesquisa, foi feito um estudo de caso no Superior Tribunal de Justiça, que possui um projeto de inclusão de deficientes auditivos. A pesquisa realizada pode ser caracterizada como descritiva e exploratória e sua abordagem qualitativa. Segundo Zanella (2009), o método qualitativo de pesquisa preocupa-se em conhecer a realidade segundo a perspectiva dos participantes da pesquisa e não utiliza elementos estatísticos para a análise dos dados. Como instrumentos de pesquisa foram utilizados roteiros para entrevistas estruturadas, observação no local de trabalho e documentos. Foram utilizados dados primários, provenientes das entrevistas e dados secundários provenientes de informações obtidas no próprio órgão. Para a análise de dados, foi utilizada a análise de conteúdo e análise documental.

\subsection{Caracterização da organização}

Criado pela Constituição Federal de 1988, o Superior Tribunal de Justiça (STJ) é a corte responsável por uniformizar a interpretação da lei federal em todo o Brasil, seguindo os princípios constitucionais e a garantia e defesa do Estado de Direito. $O$ STJ é a última instância da Justiça brasileira para as causas infraconstitucionais, não relacionadas diretamente à Constituição. Como órgão de convergência da Justiça comum, aprecia causas oriundas de todo o território nacional, em todas as vertentes jurisdicionais não-especializadas.

O STJ julga crimes comuns praticados por governadores dos estados e do Distrito Federal, crimes comuns e de responsabilidade de desembargadores dos tribunais de justiça e de conselheiros dos tribunais de contas estaduais, dos membros dos tribunais regionais federais, eleitorais e do Trabalho. 
Desde 2008, o tribunal tem investido na contratação de deficientes auditivos para o setor de digitalização. Essa ação faz parte de um projeto maior intitulado "Justiça na era virtual".

Dados recentes mostram que o número de surdos contratados mediante terceirização no tribunal já chegou a quase 300 e hoje o número é de 120 funcionários. Alguns dos deficientes auditivos trabalham como supervisores dos trabalhos.

\subsection{Participantes do Estudo}

Os participantes do estudo são pessoas envolvidas no projeto, gestores e funcionários surdos do STJ e também os funcionários da empresa terceirizada responsável pelo recrutamento e seleção.

É apresentado o perfil demográfico-funcional dos entrevistados com o objetivo de relacioná-los com as categorias que serão descritas adiante.

Foram entrevistadas 15 (quinze) pessoas sendo 1(um) Coordenador de Recursos Humanos da empresa terceirizada, 1(um) Coordenador do Projeto do tribunal, 2 (duas) Supervisoras com surdez e 11 (onze) Digitalizadores com surdez sendo 6 (seis) do sexo feminino e 5 (cinco) do sexo masculino.

Somente o coordenador de projetos é servidor do tribunal, todos os outros são contratados pela empresa terceirizada. A faixa etária dos entrevistados é de 20 a 56 anos.

A maioria dos surdos está trabalhando há quase 2 (dois) anos no tribunal.

O quadro a seguir mostra um resumo das características dos entrevistados, sendo

\begin{tabular}{|c|c|c|c|c|c|}
\hline Entrevistado & Gênero & Idade & Cargo & Escolaridade & Surdez \\
\hline E1 & Masculino & 56 & Analista/Coordenador & Superior em Direito & Não \\
\hline E2 & Masculino & 45 & Coordenador de RH & $\begin{array}{c}\text { Superior em Educação } \\
\text { Física }\end{array}$ & Não \\
\hline E3 & Feminino & 36 & Supervisor & Superior em Pedagogia & Moderada \\
\hline E4 & Feminino & 34 & Supervisor & Formanda em Letras & Moderada \\
\hline E5 & Feminino & 24 & Digitalizador & Ensino Médio & Moderada \\
\hline E6 & Feminino & 44 & Digitalizador & Ensino Médio & Profunda \\
\hline E7 & Masculino & 30 & Digitalizador & Pós-Graduação & Profunda \\
\hline
\end{tabular}




\begin{tabular}{|c|c|c|c|c|c|} 
E8 & Masculino & 36 & Digitalizador & Superior & Severa \\
\hline E9 & Feminino & 34 & Digitalizador & Ensino Médio & Moderada \\
\hline E10 & Feminino & 39 & Digitalizador & Ensino Médio & Profunda \\
\hline E11 & Feminino & 20 & Digitalizador & Superior & Profunda \\
\hline E12 & Masculino & 22 & Digitalizador & Superior & Moderada \\
\hline E13 & Masculino & 23 & Digitalizador & Ensino Médio & Profunda \\
\hline E14 & Feminino & 22 & Digitalizador & Superior & Moderada \\
\hline E15 & Masculino & 22 & Digitalizador & Ensino Médio & Severa \\
\hline
\end{tabular}

Quadro 1: Características dos entrevistados

Fonte: Dados da Pesquisa

\subsection{Caracterização dos instrumentos de pesquisa}

Para a análise dos dados primários, foram utilizados roteiros de entrevistas estruturadas como instrumentos de pesquisa. Foi elaborado um roteiro de entrevista para os gestores, coordenadores e responsáveis pela área de Gestão de Pessoas (Apêndice A) e outro para os supervisores com surdez (Apêndice $B$ ) e ainda outro para os digitalizadores com surdez (Apêndice $C$ ). Além disso, foi realizada observação do local de trabalho, em horário de expediente. Para os dados secundários foi feita a análise de dados provenientes do projeto escrito e reportagens realizadas pela assessoria de comunicação do próprio órgão.

\subsection{Procedimentos de coleta e análise de dados}

Em um primeiro momento, foi encaminhada uma carta de apresentação do estudo para a instituição, com explicações sobre o objetivo da pesquisa e pedindo a permissão e colaboração da organização (Anexo A).

Para a coleta de dados, os participantes do estudo foram divididos nos seguintes grupos:

Grupo 1: Gestores, Supervisores, Coordenador geral, Responsáveis por Gestão de pessoas, recrutamento e treinamento.

Grupo 2: Supervisores surdos, responsáveis pelo acompanhamento dos digitalizadores 
Grupo 3: Funcionários surdos que trabalham na digitalização dos processos

Dentro do universo de funcionários surdos do STJ procurou-se fazer as entrevistas por amostragem levando em consideração os diversos níveis de surdez (profundo, severo e moderado), de forma que os resultados obtidos não refletissem a realidade de apenas um determinado grupo de surdos.

Para cada um dos participantes que foi escolhido para a entrevista, apresentou-se uma carta com orientações gerais sobre a pesquisa (Anexo B). No caso dos funcionários que se comunicam apenas por LIBRAS, a mesma informação foi repassada nessa língua.

As entrevistas foram individuais sendo realizadas em Português ou em LIBRAS, conforme o caso. Os dados da entrevistas foram registrados por meio de gravações em áudio ou vídeo e por escrito. Após a coleta e degravação das entrevistas os dados foram tratados utilizando a análise de conteúdo.

Bardin (1977) conceitua a análise de conteúdo como um conjunto de técnicas de análise das comunicações visando obter, por procedimentos sistemáticos e objetivos de descrição do conteúdo das mensagens (quantitativos ou não) que permitam a inferência de conhecimentos relativos às condições de produção/recepção (variáveis inferidas) destas mensagens. A análise de conteúdo envolve três fases: a préanálise em que é feita a escolha e organização do material; a exploração do material também chamada de descrição analítica do conteúdo e por ultimo a interpretação dos resultados, correlacionando o conteúdo do material analisado com o referencial teórico (ZANELLA, 2009, p 126.).

Também foram consultados os documentos que descrevem o projeto "Justiça na era virtual", e reportagens realizadas pelo próprio departamento de comunicação do órgão. 


\section{RESULTADOS E DISCUSSÃO}

Nessa seção apresentam-se os dados obtidos a partir das entrevistas, das observações no local de trabalho e da análise de documentos.

As categorias estão divididas para cada grupo analisado. $\mathrm{O}$ grupo 1 refere-se aos coordenadores/gestores; O grupo 2 refere-se aos supervisores surdos e o grupo 3 aos digitalizadores surdos.

A primeira categoria traz a descrição do projeto e a percepção dos gestores e funcionários em relação à sua implementação. A segunda categoria busca relacionar as respostas dos participantes com a importância de conhecimentos anteriores ao trabalho. A terceira categoria trata da importância do treinamento. A quarta categoria busca analisar a percepção dos participantes em relação ao desempenho dos surdos na função. A quinta categoria trata do acompanhamento e a última, das principais causas de desligamento.

\section{CATEGORIA 1 \\ GRUPO 1: COORDENADORES/GESTORES}

Categoria 1: Descrição do projeto de inserção de deficientes auditivos no mercado de trabalho

Definição: Nessa categoria são apresentadas as principais características do projeto de inserção do surdo no tribunal.

\begin{tabular}{|l|l|}
\hline \multicolumn{1}{|c|}{ Temas } & \multicolumn{1}{|c|}{ Exemplos de Verbalizações } \\
\hline $\begin{array}{l}\text { Empresa terceirizada foi } \\
\text { contratada pelo tribunal }\end{array}$ & $\begin{array}{l}\text { E1: O tribunal contratou uma empresa sem fins lucrativos. } \\
\text { Ela fornece postos de trabalho (...) o número de } \\
\text { processos diminuiu e hoje nós estamos com } 120 \\
\text { funcionários. } \\
\text { Os surdos trabalham como } \\
\text { Eupervisores e digitalizadores de } \\
\text { processo }\end{array}$ \\
$\begin{array}{l}\text { gente tem o cuidado de entender o contexto da pessoa } \\
\text { como um todo (...) } \\
\text { E2: Eles trabalham com digitalização de processos e } \\
\text { supervisão. }\end{array}$
\end{tabular}

Quadro 2: Categoria 1/Gestores

Fonte: Dados da Pesquisa

Existe uma grande queixa da sociedade em relação à morosidade do judiciário.

Parte disso é atribuída aos trâmites burocráticos, excesso de papéis, por exemplo. 
Segundo o Superior Tribunal de Justiça, a utilização de tecnologias permite aos gestores encontrar soluções para tornar a justiça mais rápida, menos onerosa, seja do ponto de vista econômico seja em relação ao meio ambiente. Devido a isso, o STJ tomou a iniciativa de implantar o projeto "Justiça na era virtual". O processo é composto por três etapas, descritas da seguinte forma: (1) digitalização dos processos em papel que chegam ao STJ (início em janeiro/2009) e dos processos que já estavam em tramitação até aquela data; (2) implantação do sistema que permite tramitação eletrônica do processo, em todas as fases dentro do STJ; (3) integração de todos os tribunais ao sistema eletrônico, ou seja, fim do processo em papel também na segunda instância, o que levará à devolução dos processos em papel à primeira instância, até que o processo tenha início nas varas diretamente pelo computador, sem a utilização do papel.

Como parte integrante do projeto, foram contratadas pessoas com deficiência auditiva para a etapa de digitalização de processos.

\footnotetext{
Promover o respeito às diferenças e garantir o direito que todos têm de preservar sua identidade única, com as limitações e habilidades de cada um. Este é o objetivo maior do Projeto Inclusão Social, uma iniciativa estratégica do Superior Tribunal de Justiça (STJ) que vai ao encontro da vocação de uma corte que trabalha em dia com a cidadania. (STJ, 2010)
}

Conforme descrito por um dos coordenadores do projeto, o tribunal contratou uma empresa sem fins lucrativos, que fornece postos de trabalho. Inicialmente contratouse 64 deficientes auditivos. Em outubro de 2009 o número foi aumentado para 314 surdos. Desses, 290 trabalharam efetivamente na digitalização dos processos. Com o trabalho realizado, o número de processos diminuiu bastante e hoje o tribunal conta com 120 surdos trabalhando diretamente com a digitalização de processos ou nas atividades de supervisão.

Existe a figura do Supervisor, que é um surdo oralizado e que também tem o domínio da LIBRAS. Ou seja, o supervisor se comunica tanto com os digitalizadores surdos, utilizando a língua de sinais, tanto com os coordenadores e outros servidores do tribunal, utilizando a língua portuguesa oral.

O coordenador descreveu o processo de virtualização de processos composto por quatro etapas. A primeira etapa é a higienização, que corresponde à retirada dos grampos e a proteção com duas faixas elásticas para que nenhuma folha do processo seja perdida. A segunda etapa é a digitalização, feita por deficientes 
auditivos. Existe um computador e um scanner para cada funcionário. Eles digitalizam cada folha dos processos que estão no papel, salvam no sistema e depois levam para a validação. A validação é então a terceira etapa, que é feita por servidor. Eles conferem e autenticam. A quarta etapa é a indexação, também feita por servidor.

\section{CATEGORIA 2}

\section{GRUPO 1: COORDENADORES/GESTORES}

Categoria 2: Importância de conhecimentos anteriores

Definição: Nessa categoria foi ressaltada a importância de conhecimentos anteriores por parte dos funcionários surdos, não necessariamente o nível de escolaridade, mas experiência profissional, vivência, capacidade de exercer a função e também conhecimentos de informática.

\begin{tabular}{|c|c|}
\hline Temas & Exemplos de Verbalizações \\
\hline 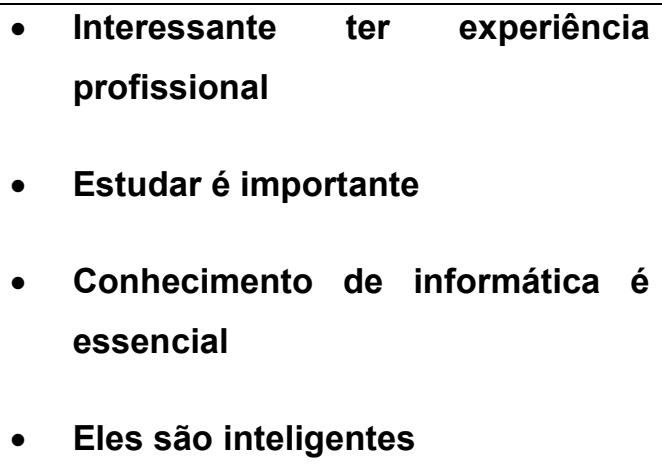 & $\begin{array}{l}\text { E1: (...) Eles estudam, tem um grau de inteligência. São } \\
\text { normais, apenas com uma limitação auditiva. } \\
\text { E2: (...) Eu não posso mandar ninguém que não tenha } \\
\text { pelo menos o conhecimento básico de informática. } \\
\text { E2: (...) A questão da escolaridade é definida no contrato } \\
\text { (...) eles deixam de estudar para trabalhar aí chega um } \\
\text { contrato que exige certo grau de escolaridade e ficamos } \\
\text { em uma situação difícil. }\end{array}$ \\
\hline
\end{tabular}

Quadro 3: Categoria 2 /Gestores

Fonte: Dados da Pesquisa

\section{GRUPO 2: SUPERVISORES}

Categoria 2: Importância de conhecimentos anteriores

\begin{tabular}{|l|l|}
\hline \multicolumn{1}{|c|}{ Temas } & \multicolumn{1}{|c|}{ Exemplos de Verbalizações } \\
\hline $\begin{array}{l}\text { É importante ter ensino médio e } \\
\text { outros cursos }\end{array}$ & $\begin{array}{l}\text { E3: "É importante ter estudo. Exigiram ter ensino médio } \\
\text { completo ou estar cursando no mínimo a oitava série" } \\
\text { E4. "Estudar é importante. Vou ajudar os surdos na } \\
\text { experiência profissional } \\
\text { educação. }\end{array}$ \\
\end{tabular}


GRUPO 3: DIGITALIZADORES

\begin{tabular}{|c|c|}
\hline \multicolumn{2}{|c|}{ Categoria 2: Importância de conhecimentos anteriores } \\
\hline Temas & Exemplos de Verbalizações \\
\hline $\begin{array}{l}\text { - Importante já possuir experiência } \\
\text { profissional } \\
\text { - É importante estudar e fazer } \\
\text { outros cursos }\end{array}$ & $\begin{array}{l}\text { E5: Já fiz curso de informática (...) } \\
\text { E6: Eu já trabalho há } 20 \text { anos (...) } \\
\text { E8: Ensinando uma profissão para surdos no futuro } \\
\text { melhora } \\
\text { E11: Eu já estudei (...) aí fica fácil entender, aprender }\end{array}$ \\
\hline
\end{tabular}

Quadro 5: Categoria 2 /Digitalizadores

Fonte: Dados da Pesquisa

Os relatos dos coordenadores e supervisores apontam para uma real importância da qualificação e do conhecimento anterior. O conhecimento básico de informática é visto como essencial para a realização do trabalho.

Mesmo um dos entrevistados tendo relatado que mais importante que a escolaridade é a capacidade de exercer a função, confirma-se, a partir dos dados demográficos, que os surdos que estão exercendo as funções têm ensino médio, superior e até pós-graduação.

Outro dado relevante é que os surdos que são oralizados têm a vantagem de se comunicar com os dois grupos, podendo então exercer a função de supervisor.

Conforme descrito por Araújo (2005) é necessário um cuidado no processo de ensino-aprendizagem das pessoas com comprometimento auditivo para que sejam desenvolvidas as competências necessárias, inerentes ao cargo que irão ocupar.

Klein (2006) ressalta que "saber fazer" não é mais suficiente para um trabalhador que almeja o sucesso. É necessário também "conhecer e, acima de tudo, saber aprender". O trabalhador, formado pela "nova" educação profissional, deve ser preparado para a iniciativa, o imprevisto, a decisão e a responsabilidade.

\section{CATEGORIA 3}

\section{GRUPO 1: COORDENADORES/GESTORES}

Categoria 3: Importância do treinamento 


\begin{tabular}{|c|c|}
\hline Ten & Exemplos de Verbalizações \\
\hline 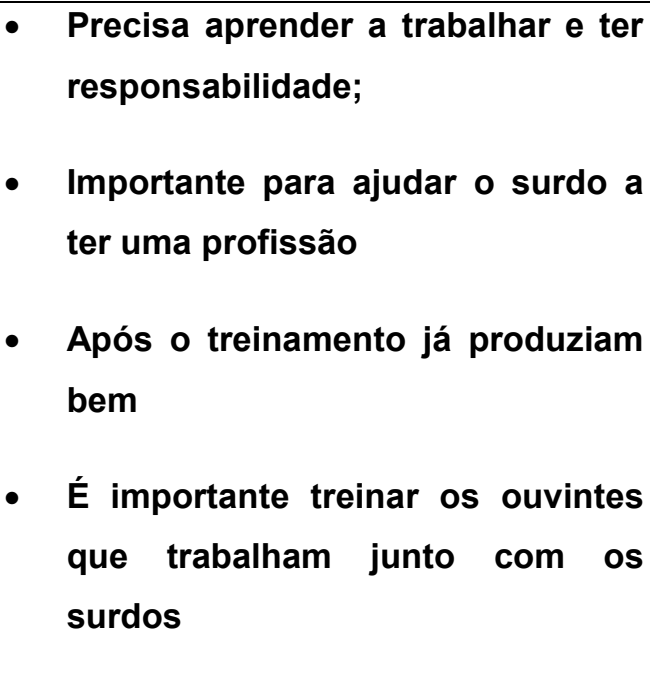 & $\begin{array}{l}\text { E1: (...) O treinamento é mais do que importante (...) o } \\
\text { tribunal deu o primeiro passo e com isso todas as } \\
\text { instituições estão copiando. } \\
\text { E1: (...) Tinha gente que não queria trabalhar, mas com } \\
\text { essa chance abriu as portas (...) } \\
\text { E2: (...) Eles fazem um treinamento no local, na prática. } \\
\text { Entender o que é digitalização, os cuidados que devem } \\
\text { ter, a responsabilidade, porque eles estão mexendo em } \\
\text { processos onde a vida das pessoas está ali dentro (...) } \\
\text { E2: }\end{array}$ \\
\hline
\end{tabular}

Quadro 6: Categoria 3 /Gestores

Fonte: Dados da Pesquisa

\section{GRUPO 2: SUPERVISORES}

\begin{tabular}{|l|l|}
\hline \multicolumn{2}{|c|}{ Categoria 3: Importância do treinamento } \\
\hline \multicolumn{2}{|c|}{ Temas } \\
$\begin{array}{l}\text { Ajuda a pessoa a trabalhar com } \\
\text { mais rapidez e agilidade; }\end{array}$
\end{tabular}

Quadro 7: Categoria 3/Supervisores

Fonte: Dados da Pesquisa

GRUPO 3: DIGITALIZADORES

Categoria 3: Importância do treinamento 
\begin{tabular}{|l|l|l|} 
- O treinamento ajudou & $\begin{array}{l}\text { E5: Primeiro ensinaram o que tinha de fazer aí fiz igual e } \\
\text { executar o trabalho } \\
\text { treinei até fica melhor } \\
\text { E6: Não teve treinamento (...) é importante para fazer } \\
\text { melhor o trabalho, mais rápido } \\
\text { E7: Ensinaram a digitalizar o papel no computador }(\ldots) \\
\text { treinamento }\end{array}$ & depois ficou mais rápido
\end{tabular}

Quadro 8: Categoria 3/Digitalizadores

Fonte: Dados da Pesquisa

Um dos conceitos abordados nesse trabalho é que o treinamento "é o conjunto de métodos usados para transmitir aos funcionários novos e antigos as habilidades necessárias para o desempenho do trabalho" (DESSLER, 2003).

O treinamento é feito no local de trabalho, em média, uma semana. Um dos coordenadores descreve o treinamento da seguinte forma:

“Eles fazem um treinamento local, na prática. Entender o que é a
digitalização, os passos da digitalização, os cuidados que devem ter, a
responsabilidade, porque eles estão mexendo em processos onde a vida
das pessoas está ali dentro, discrição no manuseio, evitar comentários
porque às vezes tem fotos, fotos comprometedoras e algo sigiloso e a gente
insiste muito nisso com eles".E2

Os supervisores destacaram a importância do treinamento para que o trabalho seja feito com mais rapidez, qualidade e agilidade. Também acrescentaram a importância do treinamento para que aprendam o trabalho, o respeito e a ética em serviço.

Os digitalizadores também consideraram o treinamento como parte importante no processo de colocação no trabalho. Interessante notar que dois dos entrevistados (digitalizadores) disseram que não houve treinamento e que seria importante, mas "não houve problema porque o trabalho é fácil".

Um dos coordenadores ressalta que o treinamento das pessoas ouvintes que irão trabalhar com os surdos é também imprescindível. Principalmente por causa da comunicação em LIBRAS. Conforme descrito por Klein (2006), é necessária a existência de ouvinte bilíngües.

Outro ponto destacado pelos supervisores é que vários órgãos públicos estão com projetos semelhantes de inclusão de surdos no setor de digitalização. Sendo assim, estão preferindo contratar os surdos já treinados no STJ e com alguma experiência na área. 


\section{CATEGORIA 4}

\section{GRUPO 1: COORDENADORES/GESTORES}

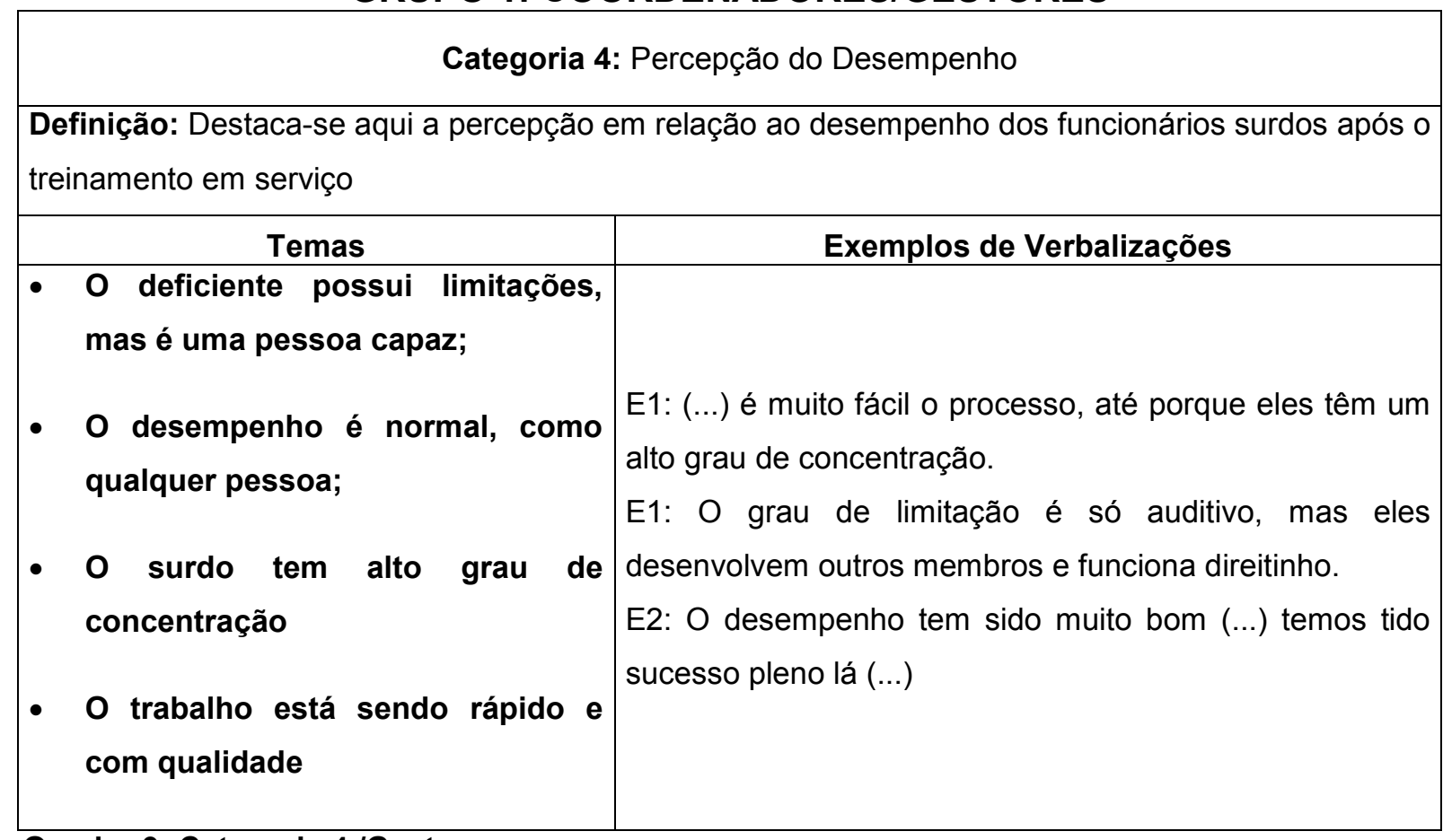

Quadro 9: Categoria 4 /Gestores

Fonte: Dados da Pesquisa

\section{GRUPO 2: SUPERVISORES}

\begin{tabular}{|c|c|}
\hline \multicolumn{2}{|c|}{ Categoria 4: Percepção do Desempenho } \\
\hline Temas & Exemplos de Verbalizações \\
\hline $\begin{array}{l}\text { - A qualidade do trabalho dos } \\
\text { surdos tem sido boa } \\
\text { - Alguns são muito bons, outros } \\
\text { são difíceis } \\
\text { - É bom para ter experiência } \\
\text { - É bom por causa da inclusão }\end{array}$ & $\begin{array}{l}\text { E3: Antes tinha surdo e ouvinte trabalhando aqui, depois } \\
\text { a produção dos surdos e a qualidade do trabalho foi muito } \\
\text { boa e agora só tem surdo na digitalização. } \\
\text { E4: Alguns são bons, outros são difíceis: chegam } \\
\text { atrasados, não obedecem aos supervisores e ainda } \\
\text { faltam. }\end{array}$ \\
\hline
\end{tabular}

Quadro 10: Categoria 4 /Supervisores

Fonte: Dados da Pesquisa

GRUPO 3: DIGITALIZADORES

Categoria 4: Percepção do Trabalho 


\begin{tabular}{|l|l|}
\hline \multicolumn{1}{|c|}{ Temas } & \multicolumn{1}{|c|}{ Exemplos de Verbalizações } \\
\hline $\begin{array}{l}\text { - o trabalho é fácil } \\
\text { importante }\end{array}$ & $\begin{array}{l}\text { E6: Eu gosto do STJ. As pessoas são boas, tem respeito } \\
\text { aqui (...) Aqui é o melhor trabalho para surdos } \\
\text { E7: Há respeito sobre a inclusão de surdos. É } \\
\text { importante... } \\
\text { E9: O trabalho é fácil (...) muito importante para mim. }\end{array}$ \\
\hline
\end{tabular}

Quadro 11: Categoria 4/Digitalizadores

Fonte: Dados da Pesquisa

Nesse relato aponta-se para um nível de concentração elevado por parte dos surdos. Um dos entrevistados relata que, mesmo sendo fácil o processo, os surdos apresentam um desempenho muito bom devido ao grau de concentração. Conforme Araújo (2005) estudos no campo da surdez indicam que as pessoas surdas, em comparação com as ouvintes, têm uma tendência a pensar mais sobre o que está sendo percebido no momento. Seu relacionamento é mais voltado para o concreto do que para o pensamento abstrato e hipotético.

Um dos entrevistados relaciona o desempenho dos funcionários com o relacionamento que eles têm com os servidores do tribunal. A comunicação é tida como parte importante que refletirá no bom desempenho dos profissionais.

\section{CATEGORIA 5}

\section{GRUPO 1: COORDENADORES/GESTORES}

Categoria 5: Necessidade de acompanhamento

Definição: Essa categoria mostra as respostas dos entrevistados em relação à necessidade de um acompanhamento continuo do trabalho realizado pelos deficientes

\begin{tabular}{|l|l|l|}
\hline \multicolumn{2}{|c|}{ Temas } & \multicolumn{1}{|c|}{ Exemplos de Verbalizações } \\
\hline $\begin{array}{l}\text { O acompanhamento é importante } \\
\text { para atingir metas }\end{array}$ & $\begin{array}{l}\text { E1: (...) A gente tem metas. Aquele que não atinge a } \\
\text { gente dá um treinamento, acompanha. }\end{array}$ \\
$\begin{array}{l}\text { É essencial para uma boa } \\
\text { comunicação entre os } \\
\text { funcionários envolvidos }\end{array}$ & $\begin{array}{l}\text { E2: Para acompanhar temos os supervisores (...) Os } \\
\text { supervisores nossos são a ponte do tribunal com os } \\
\text { surdos. } \\
\text { E2: Nossa instituição tem uma equipe de psicólogos, } \\
\text { dificuldades necessário para contornar }\end{array}$ & $\begin{array}{l}\text { assistente social, pessoas pra acompanhar e entender o } \\
\text { que está acontecendo. }\end{array}$ \\
\hline
\end{tabular}


Quadro 12: Categoria 5 /Gestores

Fonte: Dados da Pesquisa

GRUPO 2: SUPERVISORES

\begin{tabular}{|c|c|}
\hline \multicolumn{2}{|c|}{ Categoria 5: Necessidade de acompanhamento } \\
\hline Temas & Exemplos de Verbalizações \\
\hline - Os supervisores cuidam disso & $\begin{array}{l}\text { E3: Cada processo a gente sabe quem fez. Se estiver } \\
\text { errado o processo volta (...) eles mesmos arrumam. } \\
\text { E4: Supervisores sempre cuidam disso. } \\
\text { E4: Sempre conversamos se não tem ética ou } \\
\text { responsabilidade (...) ou se erram muito o trabalho. }\end{array}$ \\
\hline
\end{tabular}

Quadro 13: Categoria 5/ Supervisores

Fonte: Dados da Pesquisa

O acompanhamento é realizado principalmente pelos supervisores surdos que, conforme o relato de um dos entrevistados, são a ponte entre o tribunal e a empresa terceirizada.

Segundo Dessler (2003) o acompanhamento do desempenho pode constatar a existência de uma deficiência significativa de desempenho e determinar se essa deficiência pode ser sanada por meio de treinamento ou outras medidas.

\section{CATEGORIA 6}

\section{GRUPO 1: COORDENADORES/GESTORES}

Categoria 6: Causas de desligamento

Definição: Nessa categoria apresentam-se as principais causas de desligamento, demissão dos funcionários surdos.

\begin{tabular}{|c|c|}
\hline Temas & Exemplos de Verbalizações \\
\hline $\begin{array}{l}\text { - } \quad \text { Alguns não produzem bem } \\
\text { - } \quad \text { A maioria sai por vontade própria } \\
\text { - } \quad \text { Existe dificuldade de comunicação }\end{array}$ & $\begin{array}{l}\text { E1: (...) Alguns querem sair pra estudar pra concurso, } \\
\text { fiquei até muito feliz com isso, outros tem outras } \\
\text { dificuldades (...) } \\
\text { E2: Às vezes a pessoa tem uma dificuldade muito grande, } \\
\text { e às vezes podem ter alguma outra coisa associada (...) } \\
\text { E1: Se o problema dele é só desempenho a gente tenta } \\
\text { porque aqui o objetivo é incluir, é a inclusão. } \\
\text { E2: A gente não pode ter só esse olhar de coitadinho. }\end{array}$ \\
\hline
\end{tabular}


Tem uns que não querem trabalhar. Atrasos e faltas sem justificar nada, levam a coisa na brincadeira (...). $\mathrm{Na}$ verdade a gente faz poucas dispensas em relação ao quantitativo de surdos que temos hoje.

Quadro 14: Categoria 6 /Gestores

Fonte: Dados da Pesquisa

GRUPO 2: SUPERVISORES

\begin{tabular}{|c|l|}
\hline \multicolumn{2}{|c|}{ Categoria 6: Causas de desligamento } \\
\hline - Alguns foram devolvidos & \multicolumn{1}{|c|}{ Exemplos de Verbalizações } \\
\hline - Excesso de faltas & $\begin{array}{l}\text { E3: (...) no início eram } 390 \text { e depois de três meses o } \\
\text { trabalho tinha quase acabado e } 100 \text { foram devolvidos. } \\
\text { E4: Muita falta, discussão com o colega ou supervisor, se } \\
\text { chegava sempre atrasado }\end{array}$ \\
\hline
\end{tabular}

Quadro 15: Categoria 6 /Supervisores

Fonte: Dados da Pesquisa

Para os gestores, a principal causa de desligamento é por vontade própria do funcionário, por questões pessoais. Quando o problema é desempenho, ainda existe a tentativa de continuar, devido ao objetivo da inclusão. Mas existem os que têm muita dificuldade de realização do trabalho.

Um dos gestores destacou também os casos de funcionários que faltam sem justificativa e que não se deve ter o olhar de coitadinho.

Nesse aspecto percebe-se a mudança de visão, relatada por Klein (2006), deixando a ênfase em um controle do desvio da espécie, ou um pensamento assistencialista, partindo para uma visão de tolerância e respeito pela diversidade.

Já os supervisores destacaram o relacionamento, discussão com colegas, atrasos e excessos de faltas. Os supervisores, que estão mais próximos aos digitalizadores com deficiência auditiva, têm essa percepção. 
Parte dessa dificuldade pode estar associada à dificuldade de comunicação. Tanaka e Manzini (2005) expressam que a dificuldade para se relacionar com uma pessoa que possui deficiência, até por não saber como lhe dirigir, muitas vezes acabaria tornando um obstáculo para as empresas quando estas necessitassem contratar um funcionário com essa condição. 


\section{CONCLUSÕES E RECOMENDAÇÕES}

Os objetivos de descrever um programa de inserção de pessoas com deficiência auditiva no mercado de trabalho e de caracterizar as percepções dos atores envolvidos nesse programa foram alcançados por meio das categorias criadas para análise dos resultados.

Os resultados apresentados demonstraram a importância do treinamento da pessoa com deficiência a fim de que se profissionalize, consiga espaço no mercado de trabalho e sinta-se uma pessoa capaz e produtiva.

Conhecimentos anteriores também são importantes, nível de escolaridade é um diferencial na hora da seleção de pessoas com deficiência. Se já existe essa exigência, as pessoas com deficiência tendem a ter ainda mais dificuldade de serem inseridas no mercado de trabalho. A educação e o treinamento de pessoas com deficiência é parte essencial para sua colocação no trabalho

O treinamento das pessoas que trabalharam diretamente com os surdos é também necessário. As dificuldades de comunicação não podem ser entraves na inclusão social. É necessário engajamento, compromisso de surdos e ouvintes em colaborarem com esse processo.

Cada vez mais as pessoas têm deixado o olhar de inclusão como forma de benevolência e sim como um direito à cidadania e respeito à diversidade.

Mesmo com a entrevista tendo sido realizada em LIBRAS, os surdos digitalizadores não se delongaram nas respostas. O fato de a comunicação ter sido feita no ambiente de trabalho pode ter influenciado nas respostas pouco aprofundadas e algumas vezes superficiais, devido ao pouco tempo e o espaço não reservado. Esta foi uma das limitações da pesquisa.

Estudos na área de inclusão de pessoas com deficiência auditiva no mercado de trabalho devem ser explorados, principalmente devido à dificuldade na comunicação por intermédio de outra língua que a maioria não conhece, não domina. Podem ser realizadas pesquisas sobre programas de capacitação e treinamento de pessoas com surdez ou ainda a capacitação das pessoas que trabalham diretamente com deficientes auditivos. 
Projetos de inserção de surdos no mercado de trabalho devem ser implementados levando em consideração a capacidade de cada surdo. Outros programas de inserção no mercado de trabalho devem ser realizados, com treinamentos para a diversidade e privilegiando não as deficiências, mas a capacidade de cada surdo.

É recomendado o ensino da LIBRAS para as pessoas que terão contato com os surdos, uma política educacional séria, onde o surdo pode aprender o Português como segunda língua, podendo se comunicar pela linguagem escrita. LIBRAS assim como Braile devem fazer parte do currículo regular das escolas inclusivas. A barreira da comunicação deve ser rompida.

Espera-se que a inclusão não seja motivada somente pela lei. A lei não é o único instrumento de inclusão. Também a convivência inclusiva é essencial.

Os resultados dessa pesquisa poderão contribuir para futuras investigações sobre desafios enfrentados por empregadores e por pessoas com deficiência, especialmente as pessoas com surdez. Todos têm direito de cidadania e de valorização da diversidade humana no ambiente de trabalho 


\section{REFERÊNCIAS}

APADA. Sobre a APADA/DF. Brasília, p.1. Disponível em:

< http://www.apadadf.org.br/sobre.php>. Acesso em 29/03/2010.

ARAUJO, M. A. N. A estruturação da linguagem e a formação de conceitos na qualificação de surdos para o trabalho. Psicol. cienc. prof., vol.25, n.2, p.240-251, jun. 2005.

BARDIN, L. Análise de Conteúdo. Edições 70. Lisboa, Portugal: 1977.

BATISTA, C. BORGES, M. R.; BRANDÃO, T. MADER, G.; ALCANTARA, M. H.; SAMPAIO, D.; SASSAKI, R. Educação Profissional e Colocação no Trabalho. Federação Nacional das APAES. Brasília: 1998.

BORGES, L.; BELLO, R.; LEITE, S.; ARAUJO, R.P.C. O deficiente auditivo e o mercado de trabalho. R. Ci. Méd. Biol., Salvador, v. 1, n. 1, p. 99-104, nov. 2002.

BRASIL. Decreto ${ }^{\circ}$ 3.956, de 8 de outubro de 2001. Convenção da Organização dos Estados Americanos (Convenção de Guatemala). Disponível em:

<http://portal.mec.gov.br/seesp/arquivos/pdf/guatemala.pdf>. Acesso em 29/03/2010.

BRASIL. Decreto $\mathrm{n}^{\circ} 3298$ de 20 de dezembro de 1999. Regulamenta a Lei no 7.853, de 24 de outubro de 1989, dispõe sobre a Política Nacional para a Integração da Pessoa Portadora de Deficiência, consolida as normas de proteção, e dá outras providências. Disponível em:< http://www.planalto.gov.br/ccivil_03/decreto/D3298.htm>. Acesso em 10/03/2010.

BRASIL. Governo Federal. Constituição da República Federativa do Brasil: promulgada em 5 de outubro de 1988. Disponível em:

<http://www.planalto.gov.br/ccivil_03/Constituicao/Constitui\%C3\%A7ao.htm>. Acesso em 09/03/2010.

CARVALHO, K. M. de. Os desafios da inclusão da pessoa com deficiência no ambiente de trabalho. Centro de Estudos, Pesquisa e Prática Psicológica.

Universidade Católica de Goiás, 2009.

CARVALHO-FREITAS, M. N. de. Inserção e Gestão do Trabalho de Pessoas com Deficiência: um estudo de caso. RAC, Curitiba, v. 13, Edição Especial, art. 8, p. 121138, jun. 2009.

CARVALHO-FREITAS, M. N. ; MARQUES, A. L. (org.) Trabalho E Pessoas Com Deficiência. 1 ${ }^{\text {a }}$. Ed. Curitiba: Juruá, 2009.

CETEFE. Sobre o CETEFE. Brasília, p.1. Disponível em:

http://www.cetefe.org/index.php?option=com_content\&view=article\&id=65:saibamais\&catid=30: comunidade\&ltemid=28. Acesso em 12/11/2010

CHIAVENATO, I. Gestão de Pessoas. 3ed, Elsiever, 2008. 
DESSLER, G. Administração de Recursos Humanos. 2a . Ed. São Paulo: Pearsin Hall, 2003.

FENEIS. Contratação de surdos. Rio de Janeiro, p.1. Disponível em:

<http://www.feneis.org.br/page/contratacaodesurdos.asp>. Acesso em 29/03/2010

GOLDFELD, M. A criança surda. 2a . Ed, Plexus, 1993.

KLEIN, M. Novos textos e novos atores na formação profissional para surdos: rupturas ou permanências? Revista Brasileira de Educação v. 11 n. 33 set./dez. 2006

MARIN, C. R Góes, M. C. R. A experiência de pessoas surdas em esferas de atividade do cotidiano. Cad. CEDES, vol.26, no.69, p.231-249, Ago 2006

MOORES, Donald F. Educating the Deaf: Psychology, Principles, and Practices. 2001

NOHARA, J. J.; ACEVEDO, C. R.; FIAMMETTI, M. A vida no trabalho: as representações sociais das pessoas com deficiência. In: Trabalho e pessoas com deficiência: Pesquisas, práticas e instrumentos de diagnóstico. $1^{\mathrm{a}}$. Ed. Curitiba: Juruá, 2009.

RIBEIRO, M. F.; RIBEIRO, F. Gestão Organizacional da Diversidade: Estudo de Caso de um Programa de Inclusão de Pessoas com Deficiência. In: Trabalho e pessoas com deficiência: Pesquisas, práticas e instrumentos de diagnóstico. $1^{\mathrm{a}}$. Ed. Curitiba: Juruá, 2009.

SALLES, H. M. M. L.; FAULSTICH, E.; CARVALHO, O. L.; RAMOS, A. A. L. Ensino de Língua Portuguesa para surdos. Brasília: MEC, SEESP, 2004.

SASSAKI - Mídia e deficiência. Brasília: Andi/Fundação Banco, 2003.

SKLIAR, Carlos (Org). Educação e Exclusão: abordagens sócio-antropológicas em educação especial. Porto Alegre: Mediação, 1999.

TANAKA, E. D. O; MANZINI, E. J. O que os empregadores pensam sobre o trabalho da pessoa com deficiência? Rev. Bras. Ed. Esp., Marília, v.11, n.2, p.273-294, Mai.-Ago. 2005.

ZANELLA, L. C. H. Metodologia da pesquisa. Apostila elaborada para o curso de administração na modalidade à distância. Brasília: UnB, 2009. 


\section{APÊNDICES}




\section{Apêndice A - Roteiro de Entrevista 1}

Roteiro de Entrevista para Gestores, Coordenadores e Responsáveis pela área de Gestão de Pessoas.

1) Qual o seu nome?

2) Qual a sua idade?

3) Qual o seu cargo/função?

4) Tem conhecimento de como foi feita a seleção e recrutamento dos deficientes auditivos para exercer a função?

5) Tem conhecimento dos critérios de seleção adotados?

6) Houve treinamento?

7) Se houve, qual foi a duração?

8) Em sua opinião, qual a importância do treinamento?

9) Quais são os cargos ocupados/ atividades exercidas pelos surdos nessa instituição?

10)Qual a sua percepção em relação ao desempenho dos profissionais com deficiência auditiva nessa função?

11)Há acompanhamento do desempenho dos funcionários?

12)Se há, quais são as intervenções mais freqüentes?

13)Se houve, quais as principais causas do desligamento de surdos da organização? 


\section{Apêndice B - Roteiro de Entrevista 2}

Roteiro de Entrevista para os Supervisores com deficiência auditiva

1) Qual o seu nome?

2) Qual a sua idade?

3) Qual o seu cargo/função?

4) Qual a sua escolaridade?

5) Qual o seu nível de deficiência auditiva?

6) Já fez algum curso profissionalizante? Qual(is)?

7) Já teve experiência profissional antes dessa?

8) Como você tomou conhecimento da seleção para o trabalho no STJ?

9) Como foi feita a seleção/recrutamento?

10)Houve acessibilidade?

11)Houve treinamento?

12)Acha que o treinamento é necessário? Por quê?

13) Qual a sua percepção em relação ao trabalho que você realiza?

14)Tem conhecimento de como foi feita a seleção e recrutamento dos outros deficientes auditivos?

15)Tem conhecimento dos critérios de seleção adotados?

16)Houve treinamento?

17) Em sua opinião, qual a importância do treinamento?

18)Quais são os cargos ocupados/ atividades exercidas pelos surdos nessa instituição?

19)Qual a sua percepção em relação ao desempenho dos outros profissionais com deficiência auditiva aqui no STJ?

20)Há acompanhamento do desempenho dos funcionários?

21)Se há, quais são as intervenções mais freqüentes?

22)Se houve, quais as principais causas do desligamento de surdos da organização? 
23)Qual a importância desse trabalho pra você? 


\section{Apêndice C - Roteiro de Entrevista 3}

Roteiro de Entrevista para os Digitalizadores com deficiência auditiva

1) Qual o seu nome?

2) Qual a sua idade?

3) Qual o seu cargo/função?

4) Qual a sua escolaridade?

5) Qual o seu nível de deficiência auditiva?

6) Já fez algum curso profissionalizante? Qual(is)?

7) Já teve experiência profissional antes dessa?

8) Como você tomou conhecimento da seleção para o trabalho no STJ?

9) Como foi feita a seleção/recrutamento?

10)Houve acessibilidade?

11)Houve treinamento?

12)Se houve, como foi feito?

13)Você se sente preparado para exercer a função após o treinamento?

14)Se não houve treinamento, acha que seria necessário? Por quê?

15)Qual a sua percepção em relação ao trabalho que você realiza?

16)Qual a importância desse trabalho para você? 


\section{ANEXOS}




\section{Anexo A - Carta para a Organização}

BRASÍLIA, 13 DE OUTUBRO DE 2010.

Ao DiRetor Geral

DR.

Prezado Senhor

Estamos realizando uma pesquisa sobre a "Inserção de pessoas com deficiência auditiva no mercado de trabalho".

Diante do interesse que tem surgido na literatura científica, pela necessidade prática de se compreender melhor a realidade das organizações brasileiras no que se refere ao tema desse estudo, e pelo trabalho pioneiro realizado no STJ, solicitamos autorização para realizar a coleta de dados junto aos seus colaboradores da área de digitalização de processos.

Para isso, entregaremos questionários e realizaremos 3 entrevistas que terão duração média de 15 minutos, em horário e data a serem definidos de forma a não prejudicar as atividades profissionais dos participantes.

Esta pesquisa é vinculada ao Curso de Administração da Universidade de Brasília. Eu sou a pesquisadora responsável, meu nome é Silvia Letice e poderei ser contatada por meio do e-mail sletice@gmail.com ou pelos telefones: (61) XXXX-

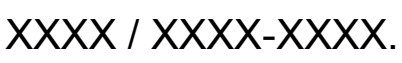

Agradecemos desde já a atenção e aguardamos o retorno quanto à viabilidade deste trabalho.

Atenciosamente, 


\section{Anexo B - Apresentação da pesquisa: orientações gerais para os entrevistados}

\section{Apresentação da pesquisa}

Prezado funcionário

Você está sendo convidado a participar de uma pesquisa sobre a pessoa com surdez/deficiência auditiva e o mercado de trabalho.

Ela é composta por uma entrevista individual com duração aproximada de 15 minutos.

Os participantes não serão identificados. As informações obtidas serão confidenciais e utilizadas exclusivamente para a realização desta pesquisa.

Queremos que você se sinta inteiramente à vontade para dar suas opiniões. Não existem respostas certas ou erradas. Se você se sentir constrangido com alguma questão, você tem o direito de recusar-se a respondê-la.

Esta pesquisa é vinculada ao Curso de Administração da Universidade de Brasília. Eu sou a pesquisadora responsável, meu nome é Silvia Letice. Se precisar poderei ser contatada por meio do e-mail sletice@gmail.com ou pelos telefones (061) xxxxxxxx / xxxxxxxx

Agradecemos desde já a sua valiosa colaboração!

Atenciosamente, 


\section{Anexo C - Fluxograma do Processo de Educação Profissional e Colocação no Trabalho}

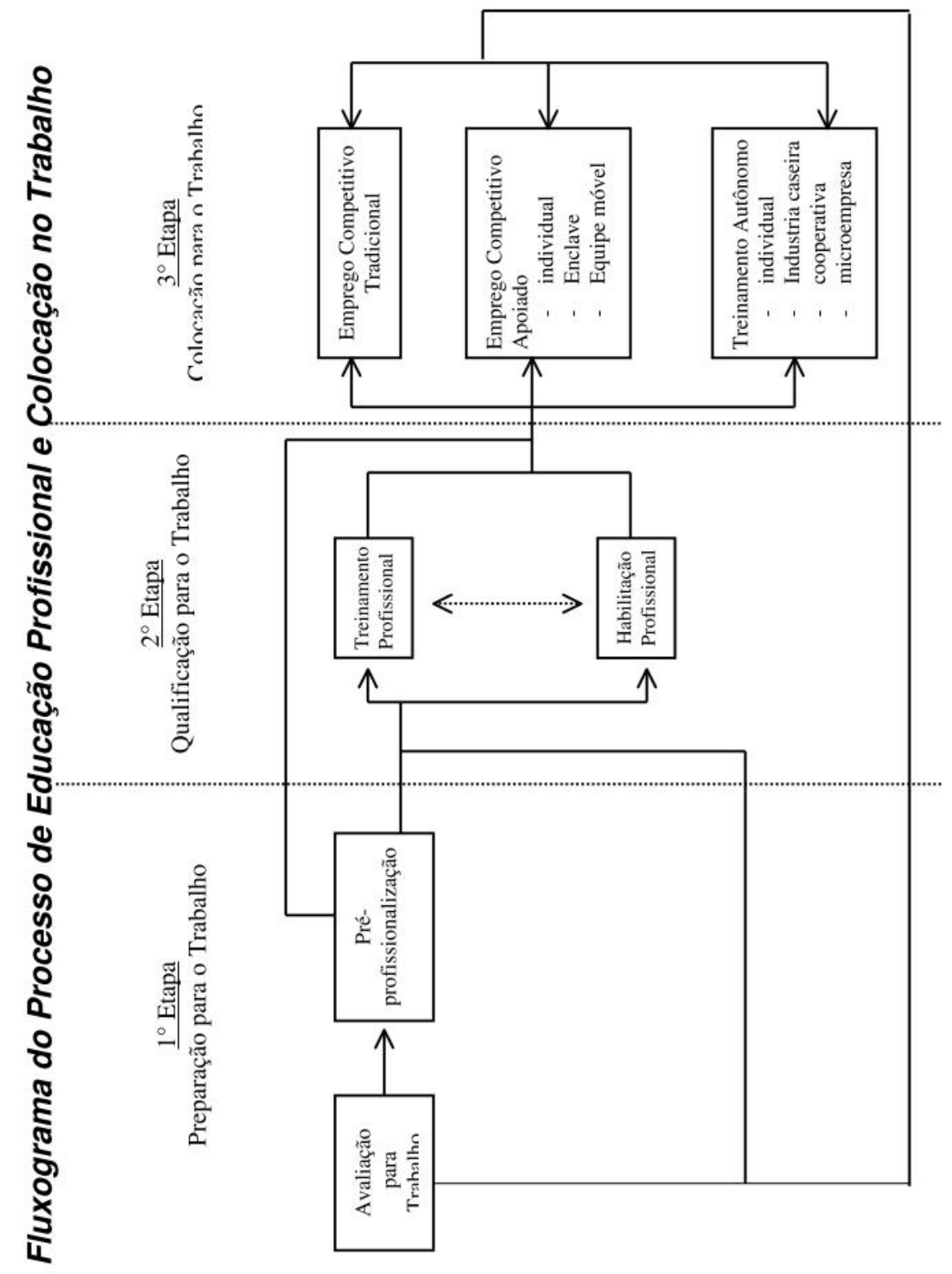

Fonte: BATISTA, C.; BORGES, M. R.; BRANDÃO, T.; MADER, G.; ALCANTARA, M. H.; SAMPAIO, D.; SASSAKI, R. Educação Profissional e Colocação no Trabalho. Federação Nacional das APAES. Brasília: 1998. 